\title{
BMJ Open Adoption of opioid-prescribing guidelines in primary care: a realist synthesis of contextual factors
}

Nora Jacobson (i) , ${ }^{1}$ Roberta A Johnson, ${ }^{2}$ Christie Schlabach, ${ }^{2}$ Jillian Incha, ${ }^{2}$ Lynn Madden, ${ }^{3,4}$ Daniel Almirall, ${ }^{5}$ Rose Hennessey Garza, ${ }^{2}$ Bri Deyo, ${ }^{2}$ Nicholas Schumacher, ${ }^{2}$ Christine Stephenson, ${ }^{2}$ Andrew Quanbeck ${ }^{2}$

To cite: Jacobson $\mathrm{N}$, Johnson RA, Schlabach C, et al. Adoption of opioidprescribing guidelines in primary care: a realist synthesis of contextual factors. BMJ Open 2021;11:e053816. doi:10.1136/ bmjopen-2021-053816

- Prepublication history and additional supplemental material for this paper are available online. To view these files, please visit the journal online (http://dx.doi.org/10.1136/ bmjopen-2021-053816).

Received 26 May 2021 Accepted 22 November 2021

Check for updates

(C) Author(s) (or their employer(s)) 2021. Re-use permitted under CC BY-NC. No commercial re-use. See rights and permissions. Published by BMJ.

${ }^{1}$ University of WisconsinMadison School of Nursing and Institute for Clinical and Translational Research, Madison, Wisconsin, USA

${ }^{2}$ Family Medicine and Community Health, University of Wisconsin-Madison, Madison, Wisconsin, USA

${ }^{3}$ Internal Medicine, Yale University School of Medicine, New Haven, Connecticut, USA

${ }^{4}$ Apt Foundation Inc, New Haven, Connecticut, USA

${ }^{5}$ Institute for Social Research, University of Michigan, Ann Arbor, Michigan, USA

Correspondence to Dr Nora Jacobson; najacobson@wisc.edu

\section{ABSTRACT}

Objective As part of an effort to design an implementation strategy tailoring tool, our research group sought to understand what is known about how contextual factors and prescriber characteristics affect the adoption of guideline-concordant opioid-prescribing practices in primary care settings.

Design We conducted a realist synthesis of 71 articles. Results We found that adoption is related to contextual factors at the individual, clinic, health system and environmental levels, which operate via intrapersonal, interpersonal, organisational and structural mechanisms. Conclusion A single static model cannot capture the complexity of the relationships between contexts, mechanisms and outcomes. Instead, a deeper understanding requires a dynamic model that conceptualises clusters of contextual factors and mechanisms that tend towards guideline concordance and clusters that tend toward non-concordance.

Trail registration number ClinicalTrial.gov registration number NCT04044521.

\section{BACKGROUND}

Opioid misuse is a significant cause of mortality and morbidity in the USA. ${ }^{1-5}$ Misuse often starts with prescribed opioids, which are also, through diversion, a source of supply to the illicit market. ${ }^{6}$ About half of all opioid prescriptions are written by primary care providers. ${ }^{7}$ The guideline for opioid prescribing in primary care issued by the US Centers for Disease Control and Prevention in 2016 recommends avoidance of high-dose prescribing, tapering for patients taking high doses, mental health screening to identify patients at high risk of misuse and overdose, signed treatment agreements and regular urine drug screening. ${ }^{8}$ Many jurisdictions also mandate use of prescription drug-monitoring programmes (PDMPs), electronic databases that track prescriptions for opioids. ${ }^{9}$ As is common with many guidelines, these practices have been adopted unevenly and thus have become a focus of implementation interventions. ${ }^{1011}$

\section{Strengths and limitations of this study}

- Realist synthesis takes an expansive approach to evidence, allowing for the integration of both qualitative and quantitative research.

- The exploratory and iterative nature of realist synthesis was appropriate for the enlightenment aims of our research, but it did not allow us to determine the relative importance of the factors and mechanisms identified.

- Because there are gaps and limitations in the extant evidence, the synthesis could not be exhaustive across contextual levels and mechanisms.

- The synthesis included only articles published in English that reported research in middle-income and upper-income countries.

The work reported here is part of the Balanced Opioid Initiative, a programme of research that uses systems consultation, an approach based on systems engineering principles, to promote the implementation of guideline-concordant opioid-prescribing practices in primary care. ${ }^{12}$ Systems consultation blends four implementation strategies: educational meetings, performance feedback, practice facilitation and prescriber peer consulting. ${ }^{13}$ These strategies have different targets (the healthcare system, the clinic and the individual prescriber ${ }^{14}$ ) and seek to address different kinds of problemsfor example, lack of information about prescribing patterns, unfavourable workflows and patient complexity-that are barriers to the adoption of guideline-concordant practices. $^{15}$

A pilot test of systems consultation led our team to note that contextual factors at the healthcare system, clinic and prescriber levels seem to be associated with clinics' implementation trajectories. ${ }^{15}$ An understanding of context may hold the key to designing tailored packages of implementation 
strategies. As part of an effort to design a tailoring tool, our team conducted a realist synthesis to explore what is known about how contextual factors and prescriber characteristics affect the adoption of guideline-concordant opioid-prescribing practices in primary care.

\section{Approach: realist synthesis}

Realist synthesis conceptualises the outcomes of interventions as the result of interactions between mechanism(s) of change and the context(s) in which the intervention takes place. This context/mechanisms/outcomes formulation scaffolds the questions that drive the approach: 'What works for whom, in what circumstances, in what respects, and how' ${ }^{16}$ Following Shaw et al, ${ }^{17}$ we define context as 'the circumstances...that can be broken into meaningful segments and further specified' and mechanisms as the 'underlying entities, processes, or structures that operate in particular contexts to generate outcomes of interest'. In this synthesis, our outcome of interest is concordance or non-concordance with guideline opioidprescribing practices. We seek to understand the mechanisms through which contextual factors may affect this outcome.

Realist synthesis has four phases: in phase 1, the scope of the synthesis is defined; in phase 2, evidence is identified, gathered and appraised; in phase 3 , the evidence is extracted and synthesised; and in phase 4 , results of the synthesis are used to draw conclusions and findings are disseminated. Because this approach is iterative, the scope is subject to revision. Figure 1 summarises the conduct of our synthesis.

- Phase 1: We wanted to understand how context operates during the adoption of evidence-based practices in primary care so that we could integrate contextual factors into an implementation tailoring tool. Initially, the team envisioned a generic tool that could be used to tailor the implementation of any evidencebased practice. As we began, in phase 2, to recognise the breadth of the extant literature, our purpose narrowed, coming to focus on the complementary questions of the role of contextual factors in either promoting or hindering the adoption of guidelineconcordant opioid-prescribing practices in primary care (synthesis 1), and the association between prescriber characteristics and guideline adoption (synthesis 2). Our final scoping statements are shown in box 1.

- Phase 2: A research librarian, in collaboration with the research team, developed a list of Medical Subject Headings (MeSH) keywords that were combined with other parameters specified in the scoping statements (ie, publication in the last 5 years, in English, and focused on middle-income or upper-income

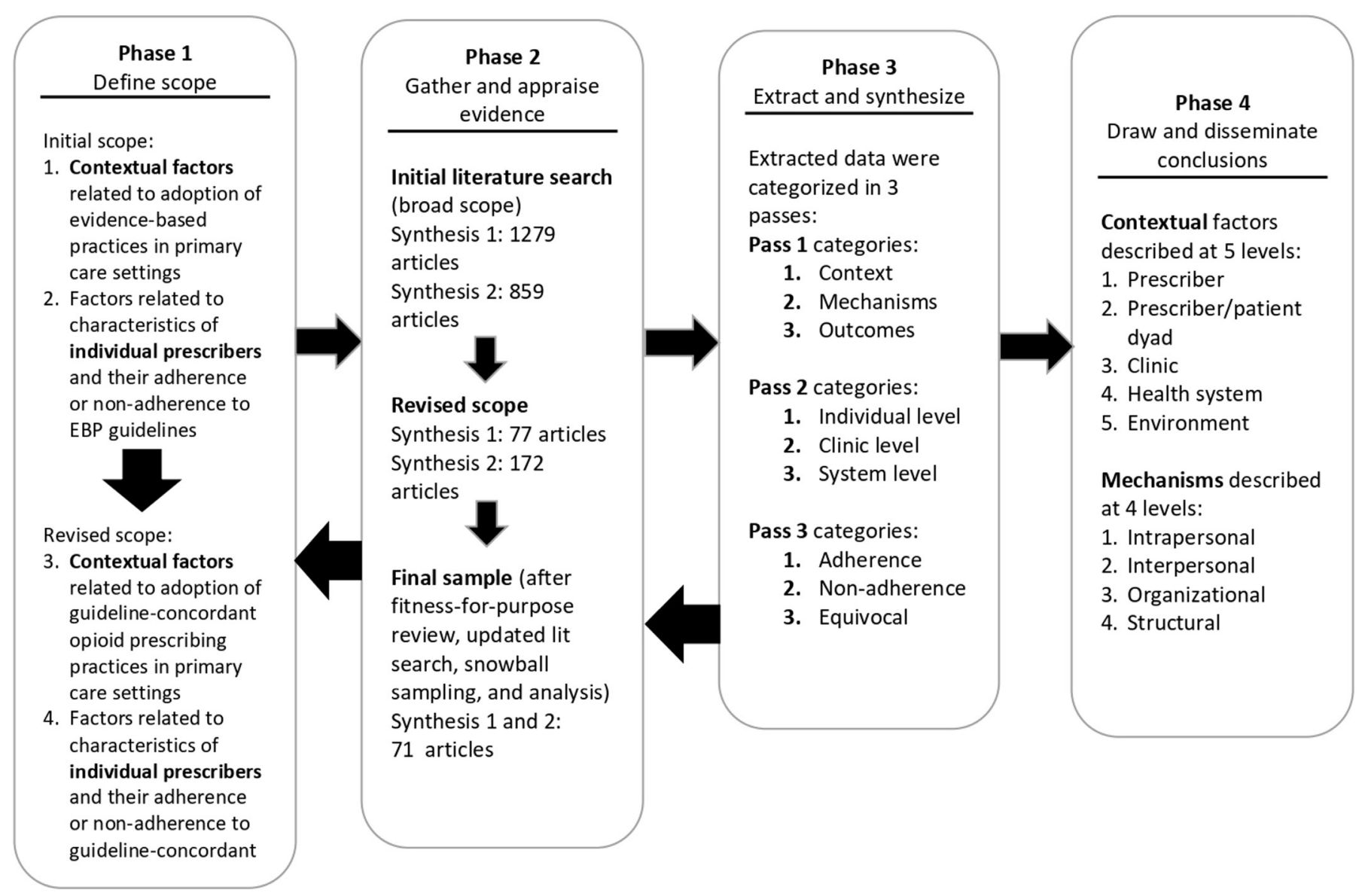

Figure 1 Summary of the realist synthesis. 


\section{Box 1 Scoping statements}

Synthesis 1: contextual factors related to opioid prescribing in primary care settings

We are interested in research that

- Deals with the implementation of guideline practices related to opioid prescribing in primary care settings.

- Given the changing landscape of primary care and the relative recency of the emphasis on promoting opioid-prescribing guidelines, we will limit our search to the last 5 years.

- Additionally, we will limit ourselves to research published in English that is focused on high-income/middle-income or upper-income countries.

\section{Synthesis 2: factors related to individual prescribers}

We are interested in research that

- Examines what is known about the relationship between individual prescriber characteristics and adherence/non-adherence to guideline practices for opioid prescribing.

- Focuses on primary care prescribers working in primary care settings.

- Is limited to the last 5 years.

- Is limited to research published in English that is focused on highincome/middle-income or upper-income countries.

countries) and used to search PubMed, Scopus, PsycINFO, CINAHL, ERIC and SocINDEX, resulting in more than 2000 citations. The citation titles were reviewed for relevance. At this point, the team recognised that the plan was too ambitious for its available resources and narrowed the review to the scope shown in box 1 . The list of citations was again reviewed. Articles whose titles suggested a match with the narrower scope were retrieved. The criterion used to make decisions about article inclusion was the relevance of the research to our scope. ${ }^{16}$ This sampling strategy, based on the assumption that 'every meaning matters', tends to err toward inclusion and was justified by the broad aim of our synthesis. ${ }^{18} 19$ An additional search was performed to make sure we were capturing the most recent publications. The article selection process is summarised in figure 1 . In total, 71 articles were included in the final synthesis. ${ }^{1520-89}$ (A list of MeSH search terms used that are relevant to the revised scope is available in the online supplemental file).

- Phase 3: The team developed two extraction tools, one for each scoping statement. Extraction domains included context, mechanisms and outcomes, as well as study details. All extracted material was entered into spreadsheets. Analysis focused on 'concept mining and theory formulation' 18 and 'unpack(ing) the mechanism $[\mathrm{s}]^{16}$ and unfolded in four passes. First, the extracted data were categorised as describing (1) context, (2) mechanisms or (3) outcomes; second, it was categorised as pertaining to one or more of three broad domains: the individual, clinic or health system; and third, as tending toward (guideline) adoption or non-adoption or being equivocal as to adoption. In the final pass, a form of retroductive theorising or 'uncovering hidden mechanisms of action' was used to review explicit and implicit data about mechanisms and construct short narrative explanations of how specific contextual factors appeared to result in adoption outcomes. ${ }^{90}$ Analysis was supported by the construction of visual displays and memo writing. During analysis, the initial domains of context-individual, clinic and health system, which were embedded in the model that influenced our implementation intervention-were further refined. Specifically, we added the domain of prescriber-patient dyad factors to account for evidence we reviewed about how characteristics of the relationship seem to affect guideline adoption as well as the domain of environmental factors to capture evidence about how the broader sociostructural context affects the adoption behaviours of individuals and organisations. As the last step, the two syntheses laid out in the scoping document were found to be intertwined via the identified mechanisms and were collapsed.

- Phase 4: The findings have been used to develop a tailoring tool which is being tested and will be reported in future publications.

\section{Patient and public involvement}

There was no patient or public involvement in the conceptualisation or conduct of this synthesis.

\section{FINDINGS}

\section{Contextual factors}

We identified contextual factors operating at five levels: prescriber, prescriber-patient dyad, clinic, health system and environment. These are summarised in table 1.

Prescriber demographic factors. $2426294450-525456616365727879$ Specialty type is the only demographic factor clearly associated with guideline adoption. Specialties that develop long-term relationships with patients, as well as those focused on pain medicine, are more likely to adopt. Being a foreign medical graduate is associated with nonadoption as is being a non-physician prescriber. Other demographic factors, such as age, sex and years of practice, are equivocal in their relationships to adoption. For example, in some studies, older prescribers and male prescribers are more likely to be guideline-concordant; in others, it is younger and female prescribers.

Prescriber experiential factors. ${ }^{24}$ 37-3941 $4244505254-575971798084$ Prescribers with certain training are more likely to adopt. Specifically, training in palliative care, pain management and mental healthcare and/or addiction medicine is associated with adoption. High-volume prescribers who frequently prescribe opioids are more likely to adopt. Prescribers whose practices include prescribing medications for opioid use disorder are more likely to demonstrate guideline concordance. Prescribers who know someone who has been treated for an opioid overdose tend towards adoption. Clinicians who are less likely to adopt are low-volume, low-dose prescribers or non-prescribers. 
Table 1 Contextual factors

\section{Contextual}

factors

\section{Outcomes}

\begin{tabular}{ll}
\hline \multicolumn{2}{c}{ Tending toward non-adherence } \\
Prescriber level \\
Demographic & Foreign medical graduate \\
Experiential & $\begin{array}{l}\text { Low-volume, low-dose prescribing } \\
\text { Pharmaceutical company-sponsored training in } \\
\text { opioids } \\
\text { Incentives from pharmaceutical companies }\end{array}$
\end{tabular}

Equivocal

Tending toward adherence

\section{Age, sex, training status, years of Specialty type} practice, practice location

Incentives from pharmaceutical companies

\section{Attitudinal \\ Scepticism about guideline \\ Guideline necessary only for 'red flag' patients \\ 'My patients' are not at high risk of opioid-related harms. \\ Guidelines protect prescribers, not patients. \\ Guideline is a law enforcement activity. \\ Disagree with specific elements of guideline (eg, \\ utility of tapering) \\ Opioids are the only effective treatment for pain. \\ Tapering and discontinuation are too difficult to \\ implement. \\ Some people function better with opioids. \\ Not concerned about addiction or overdose \\ Solely focused on opioid-related harms \\ Do not distinguish between dependence and addiction}

Psychological Exhibit signs of burn-out

Negative feelings about patients, practice,

opioids and opioid prescribing

Lack of motivation to adhere with guideline care

Training in palliative care, pain management, mental health, addiction medicine

Frequent, high-volume opioid prescribing

Medication for opioid use disorder prescribing

Knowing someone who has died of an opioid overdose

High priority on pain treatment Positive attitudes toward opioids for pain treatment Concern about possibility of opioid dependence

Prescribers should protect patients from harms of opioids Opioid use disorder as a chronic disease

Awareness and positive attitude towards opioid-prescribing guideline

Believe they have the knowledge and resources they need to provide guideline-concordant care

Comfortable with opioid prescribing

Satisfaction with practice

\section{Prescriber-patient dyad factors}

Negative prescriber attitudes toward patients Relationship discontinuity

Patient passivity/assertiveness

Patient cultural beliefs

Familiarity

Relationship continuity

Patient-centred and 'wholeperson' care

Clinic factors

Turf battles

Clinician conflict about opioids and opioid prescribing

Health system factors

High demand/low support

Workflows do not accommodate guideline care. Administrative intrusion into clinical decisionmaking

Inadequate prescriber compensation

Compensation arrangements
Team-based culture Interdisciplinarity

Culture of QI
Type of health system

Size of health system

Location of health system
Clear policies toward opioid prescribing, including mandates Resources devoted to supporting guideline adherence

Environmental factors

Aggressive marketing by pharmaceutical
companies
Poverty
Health disparities

Media focus on opioid misuse Moral panic

High rates of opioid prescribing

High numbers of overdose deaths
Pressure from regulatory agencies Clinical guidelines 
Non-adoption is also associated with having received pharmaceutical company-sponsored training in opioid prescribing and a history of having accepted incentives from pharmaceutical companies.

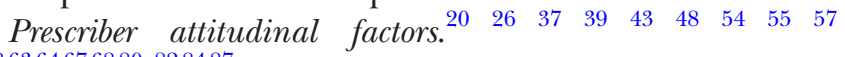
${ }^{586364676880-828487}$ Prescriber attitudes toward pain, opioids and guidelines are related to concordance. Concordant prescribers believe that treating pain is a priority and are positive about the effectiveness of opioids for chronic pain. However, they are concerned about patient dependence and see the prescriber role as being one of protecting patients from opioid-related harms. They conceptualise opioid use disorder as a chronic disease. They are aware of recommended opioid-prescribing practices and believe they are effective in protecting patients. In addition, they report having the knowledge and resources necessary to provide guideline-concordant care. Non-adopting prescribers express more scepticism, perceiving guidelines are necessary only for patients who present with 'red flags.' They do not see addiction and overdose as concern for their patients. They believe that guidelines provide protection for the prescriber but have no real patient benefit, and view them mainly as a law enforcement activity. Non-adopting prescribers disagree with some of the recommended practices. For example, they think that there is no need to reduce a patient's dose if the patient is stable, that guidelines themselves may contribute to misuse by calling for dosages that are too low for pain control, and that tapering and discontinuation are too difficult to implement. They often see opioids as the only effective treatment for pain, believe that some people function better when taking opioids, are not very concerned about addiction and overdose, or are solely focused on the risks of opioids, and do not distinguish between dependence and addiction.

Prescriber psychological factors. ${ }^{29} 404147526481$ Concordant providers feel comfortable prescribing opioids. Prescribers who tend toward adoption also express general satisfaction with their practice situations. For non-concordant providers, the picture is darker. They show many signs of burn-out, including feeling overwhelmed and frustrated and emotionally drained by their patients. Their feelings about opioid prescribing are negative. They report that they are not in control of the opioid-prescribing process and that their workplaces provide them with little support related to prescribing. They are very worried about the possible negative consequences of opioid prescribing, both for their patients and for themselves. They also report a lack of motivation related to guideline adoption.

Prescriber-patient dyad level. ${ }^{25} 27 \quad 283234394042 \quad 4345-47$ $535761656668-707780-838788$ Adoption of guideline practices is supported when prescribers use patient-centred and 'whole-person' psychosocial frameworks and when there is continuity in the prescriber-patient relationship. In non-adopting dyads, prescribers often perceive patients who use opioids as 'difficult', that is, demanding, resistant to medical advice and dissatisfied with their care.
Perceived patient assertiveness or passivity and patients' cultural beliefs are equivocal factors.

Clinic level. ${ }^{15} 22242531$ 33-36 41-43 47 52 57-59 62667074798689 Guideline adoption is promoted when a clinic has a teambased culture of interdisciplinarity, such as engagement of non-physician providers with physicians, pharmacist involvement in patient care and access to pain specialists. Guideline-concordant clinics tend to value and have experience implementing workflow-focused quality improvement processes. The clinic maintains adequate staffing. By contrast, non-adoption is more likely in high-demand/low-support clinics where clinicians are assigned large patient panels and see high numbers of patients each week. Resources are scarce and clinicians have turf battles and hold incompatible views about opioids and opioid-prescribing practices. Workflows do not accommodate the processes necessary for guideline care. For example, the clinic lacks tools or procedures to enable the monitoring of patients who are using prescription opioids.

Health system level. ${ }^{21} 22303142-4458636570-727576858688$ Health systems that tend toward adoption have policies related to opioid prescribing that have been clearly spelled out, widely promulgated, and include mandates and the resources needed to support concordance. The system has invested in electronic health record tools that provide data on opioid prescribing and has instituted incentives for guideline adherence. Systems tending toward nonadoption demonstrate the high demand/low support conditions described previously. Prescribing clinicians perceive administrative intrusions on their practice and feel inadequately compensated. Physicians' incomes are at least partially dependent on patient satisfaction measures, and physicians feel personally responsible for the financial health of the practice. The system allows prescribers to accept education and financial incentives from the pharmaceutical industry. There is some indication that safety net settings and health systems operating in rural locations-both of which tend to be under-resourced and to serve populations with high rates of opioid usemay tend towards non-adoption; other research suggests that type of practice, size of practice and location (rural/ urban) of practice are equivocal.

Environmental level. 2628313437394748525758626973828489 Pressure from regulatory agencies-for example, statemandated use of the PDMP-and clinical guidelines promote adoption. Aggressive marketing of opioids works against it. When health services are provided in a sociostructural context characterised by poverty and severe health disparities-for example, in safety net clinics or practices located in disadvantaged communities-there is a tendency towards non-adoption. Equivocal factors include a media focus on opioid misuse and an atmosphere of moral panic surrounding opioids. At a population level, high rates of opioid prescribing and high numbers of overdose deaths are also equivocal in their impact on guideline concordance. 


\begin{tabular}{|c|c|c|}
\hline \multirow{2}{*}{$\begin{array}{l}\text { Type of } \\
\text { mechanism }\end{array}$} & \multicolumn{2}{|c|}{ Example mechanisms } \\
\hline & Adherence & Non-adherence \\
\hline Intrapersonal & Confidence & Cognitive load \\
\hline Interpersonal & $\begin{array}{l}\text { Mutual trust } \\
\text { Collaboration }\end{array}$ & $\begin{array}{l}\text { Frustration } \\
\text { Fear } \\
\text { Conflict }\end{array}$ \\
\hline Organisational & Leadership & Financial incentives \\
\hline Structural & $\begin{array}{l}\text { Awareness raising } \\
\text { Fear }\end{array}$ & $\begin{array}{l}\text { Hardening of negative } \\
\text { attitudes }\end{array}$ \\
\hline
\end{tabular}

\section{Mechanisms}

Mechanisms are explanations of how these contextual factors work to affect adoption outcomes. Mechanisms are summarised in table 2.

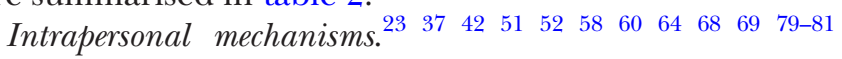
Prescriber confidence appears to be a key mechanism promoting concordance. Clinicians who have relevant specialty training and/or years of experience treating chronic pain report feeling comfortable prescribing opioids and are confident in their abilities to do so in ways that minimise harm. This group is more likely to be aware of guideline practices and is able to implement them because they have the skills needed to make risk assessments and manage tapering. (However, the phenomenon of 'ego bias', or an overabundance of confidence, seems linked to non-adoption.) Cognitive load appears to be a mechanism associated with non-adoption. When clinicians feel overwhelmed by the demands of practice, they are more likely to have negative attitudes towards opioids and to be wary of the complex and time-consuming work created by prescribing guidelines.

Interpersonal mechanisms. ${ }^{22} 25$ 27-32 3536 41-43 45-4752 535661 6266 68-70 74 81-8389 Two types of interpersonal relationships are important to guideline concordance: those between prescribers and their patients and those within groups of prescribers.

In prescriber-patient dyads that tend towards adoption, mutual trust promotes guideline concordance. Trust provides a basis for the difficult conversations required to initiate urine drug screening and tapering. When patients trust their providers, they are more likely to speak openly about their opioid use and to be willing to try alternative approaches to managing chronic pain. When prescribers trust their patients, they are less likely to feel personally threatened by a range of potential patient responses to guideline practices. For example, they don't worry that they will suffer financially because the patient will choose to leave the practice if required to undergo regular urine drug screening. In non-concordant dyads, frustration and fear appear to be significant mechanisms. Here, nonadoption results from a complex interplay among patient and prescriber characteristics. Patients stigmatised as 'difficult' tend to be both medically complex and psychologically fragile. They take more of the prescriber's attention, which both increases the prescriber's cognitive load and reduces the amount of time available to discuss issues like tapering. Prescribers report sometimes feeling frightened by these patients, worried, for example, that conflict over opioids may lead to violence. Prescribers may be more likely to hold these stigmatising perceptions with members of historically marginalised communities, such as people who are poor, people with low health literacy or limited English proficiency, and people who are racial or ethnic minorities.

Among prescribers and other clinical staff, collaboration supports guideline adoption. Primary care prescribers, including non-physician providers like advanced practice registered nurses and physician assistants, gain in confidence when they are able to consult with colleagues who have greater expertise. Teambased care models reinforce communication between providers, thus promoting consistent messaging and behaviour around opioid prescribing. Responsibility efficiently shared across interdisciplinary providers may reduce cognitive load. Conversely, conflict between clinicians seems to be linked to non-adoption. Conflict arises when individual prescribers have different attitudes towards opioids and different approaches to opioid prescribing and find themselves confronted with these differences. For example, when a prescriber inherits patients from a colleague who has been prescribing extremely high doses of opioids, tapering is difficult. In some settings, conflict is intergenerational, with residents and other newer physicians who have been trained since the beginning of the opioid crisis being more reluctant to prescribe when compared with their more experienced colleagues.

Organisational mechanisms. 1521343644627074758586 Health system-level or clinic-level policies and cultural norms affect opioid-prescribing behaviour. Leadership promotes guideline concordance: high-level endorsement of guideline prescribing, reinforced through the allocation of adequate resources-such as investment in monitoring and display technologies like opioid prescription dashboards-allows guideline care to become embedded in clinic workflows. Adverse financial incentives promote non-adoption. For example, when prescribers' livelihoods are tied to patient satisfaction measures, prescribers may be reluctant to implement practices such as urine drug screening that can alienate patients.

Structural mechanisms. ${ }^{34} 394857626982$ Adoption is affected by larger social, political, historical or environmental factors. The rise of opioids as a public problem has triggered regimes of surveillance that have worked both to support and to hinder guideline adoption. Statemandated elements of guideline concordance, such as the PDMP, have promoted adoption via both positive mechanisms such as awareness raising and negative ones such as fear of medicolegal consequences. Perceptions of monitoring as primarily a law enforcement activity, however, may promote non-concordance by hardening prescribers' negative attitudes towards opioids. 


\section{DISCUSSION}

We aimed to explore the role played by contextual factors and mechanisms in opioid-prescribing guideline adoption in order to improve guideline implementation. The findings have supported the soundness of what Ferlie and Shortell ${ }^{14}$ describe as a 'comprehensive, multi-level approach to change', such as systems consultation.

\section{Dynamic model}

The concepts of context and mechanism are heuristics. The distinction between context and mechanism changes as we shift the focus of our inquiry from the individual prescriber to the prescriber-patient dyad and from the clinic or healthcare system to the environment. ${ }^{17}$ The boundaries between the intrapersonal, interpersonal, organisational and structural are permeable, and mechanisms are mutually reinforcing and mutually diminishing such that they cannot be said to operate independently. Structural mechanisms are enacted in factors that manifest at the organisational level, which then affect individual behaviour. For example, the relationship between guideline concordance and patients' socioeconomic and ethnoracial status reflects societal patterns of inequity that result in inadequate resources being allocated to the safety net settings where many of these patients receive care, which in turn results in greater cognitive load at the prescriber level, which results in less guideline concordance.

The complexity of the contextual factors and mechanisms included in this review-combined with the limitations of the extant research that we discuss further-defies development of a static model of how context affects adoption of guideline-concordant opioid-prescribing practices. Instead, this synthesis suggests that adoption outcomes result from dynamic interaction among factors and mechanisms. ${ }^{91}$ Adoption and non-adoption are associated with clusters of contextual factors and mechanisms. This review could not determine which elements of a cluster are necessary or sufficient for adoption, nor how single contextual factors or mechanisms may mediate or moderate outcomes in specific settings. We are not able to make statements about which factors are universally important and thus should be prioritised for intervention. However, this review does suggest the domains and some of the specific factors and mechanisms that should be considered when developing implementation interventions in specific settings.

\section{Equivocal evidence}

Equivocal refers to several different situations: first, when the evidence is incomplete, we do not know much about how a factor such as practice type affects adoption because it has not been researched adequately; second, when the evidence is contradictory: as noted, studies have suggested that male prescribers are both more and less likely to be guideline-concordant than female prescribers; and third, when the evidence is nuanced: for example, confidence in one's ability to prescribe safely promotes adoption, except when confidence becomes hubris (or ego bias), which is associated with non-adoption. Missing evidence can be filled in by targeting future research. Contradictory evidence may be resolved by applying a broader lens, asking, for example, which conditions favour male prescribers' adoption and which favour female prescribers' adoption. Nuanced evidence may be clarified by drawing on other disciplines, such as work in psychology that might help us understand hubris.

\section{Definitions of adoption}

Research on adoption of opioid-prescribing guidelines looks both at prescription initiation and ongoing prescribing and conceptualises concordance inconsistently. In some studies, guideline concordance is defined only as actions that tend to limit patient access to and use of opioids. In others, concordance is understood as actions that promote appropriate access and use. This difference reflects a growing recognition of the patient harms that were an unintended consequence following dissemination of the Centers for Disease Control and Prevention's 2016 guideline. ${ }^{892} 93$ We accepted the judgements of the original authors of articles included in the synthesis as to definitions of adoption, but that choice elides an important philosophical difference.

Most of the extant research on adoption looks at a single opioid-prescribing practice or different combinations of practices, not necessarily a consistent set of practices as defined by one widely accepted guideline. There is some indication that concordance may be a package deal; that is, prescribers who are concordant with one guideline practice tend to be concordant with all of them. ${ }^{50}$ However, this has not been firmly established. For the purposes of this synthesis, we defined concordance as being concordant with any practice and any guideline. Of course, this decision limited our ability to develop a more granular understanding of any differential impact of context on single opioid-prescribing practices or the bundles of practices defined by specific guidelines.

\section{Limitations}

The limitations of this synthesis in part reflect limitations in the original research. The published literature has been very focused on individual-level factors, particularly the associations between prescriber characteristics and guideline adoption. Assessment of patient-level factors tends to be from the prescriber perspective and thus tends to say more about prescriber attitudes than it does patient experiences. Little is known about contextual factors at the clinic, health system and environmental levels. There is very little evidence about mechanisms. Some investigators have offered theories of how identified contextual factors lead to adoption outcomes, but the focus of the research thus far has been on identifying causal or correlational relationships, not explicating the underlying mechanisms. A second set of limitations results from decisions we made in conducting the research. Although the field is gathering evidence about the effectiveness of 
specific implementation interventions, we did not look at the interaction between contextual factors and the mechanisms of change embedded in these interventions. ${ }^{11}$ Realist synthesis, an approach that was well suited to the aims of our research, is focused on theory generation, not summative evaluation. Our synthesis was limited to articles published in English and focused on middle-income or upper-income countries, and thus we may have missed some relevant research. As a result of these limitations, this synthesis cannot be exhaustive across the different levels of factors and types of mechanisms and cannot offer evidence-based determinations about the relative importance of the factors and mechanisms we have identified.

\section{Conclusion}

Adoption of guideline-concordant opioid-prescribing practices in primary care is related to contextual factors at the individual, dyadic, clinic, health system and environmental levels, which operate via intrapersonal, interpersonal, organisational and structural mechanisms. A static model cannot capture the complexity of the relationships between context, mechanisms and outcomes. Instead, deeper understanding requires a dynamic model that conceptualises clusters of contextual factors and mechanisms that tend toward guideline concordance and clusters that tend toward non-concordance. The state of the science does not yet allow us to grasp the inner workings of these clusters. Further research should develop more sophisticated understanding of the mechanisms through which contextual factors affect adoption outcomes.

Acknowledgements The authors are grateful to Mary Hitchcock, senior academic librarian at the University of Wisconsin-Madison Ebling Library, for her assistance with this review.

Contributors NJ, RAJ, CSc, JI, LM, DA, RHG, BD, NS, CSt and AQ were members of the working group that conceived the synthesis, provided feedback on its conduct, and reviewed and approved the final manuscript. $\mathrm{NJ}$ designed the synthesis, reviewed citations, led the analysis and drafted the manuscript. She is the the guarantor for the article. RAJ drafted the manuscript. CSc, CSt and Jl reviewed the citations and extracted the articles. $A Q$ is principal investigator of the Balanced Opioid Initiative and drafted the manuscript.

Funding The research reported in this publication was supported by the National Institute on Drug Abuse of the National Institutes of Health (award number R01DA047279). The content is solely the responsibility of the authors and does not necessarily represent the official views of the National Institutes of Health.

Competing interests None declared.

Patient consent for publication Not applicable.

Ethics approval This synthesis did not involve human or animal subjects and thus did not undergo ethics review.

Provenance and peer review Not commissioned; externally peer reviewed.

Data availability statement Data sharing is not applicable as no datasets were generated and/or analysed for this study.

Supplemental material This content has been supplied by the author(s). It has not been vetted by BMJ Publishing Group Limited (BMJ) and may not have been peer-reviewed. Any opinions or recommendations discussed are solely those of the author(s) and are not endorsed by BMJ. BMJ disclaims all liability and responsibility arising from any reliance placed on the content. Where the content includes any translated material, BMJ does not warrant the accuracy and reliability of the translations (including but not limited to local regulations, clinical guidelines, terminology, drug names and drug dosages), and is not responsible for any error and/or omissions arising from translation and adaptation or otherwise.
Open access This is an open access article distributed in accordance with the Creative Commons Attribution Non Commercial (CC BY-NC 4.0) license, which permits others to distribute, remix, adapt, build upon this work non-commercially, and license their derivative works on different terms, provided the original work is properly cited, appropriate credit is given, any changes made indicated, and the use is non-commercial. See: http://creativecommons.org/licenses/by-nc/4.0/.

ORCID iD

Nora Jacobson http://orcid.org/0000-0002-5118-8475

\section{REFERENCES}

1 Ahmad F, Rossen L, Sutton P. Provisional drug overdose death counts. Vital statistics rapid release provisional drug overdose death counts, 2021. Available: https://www.cdc.gov/nchs/nvss/vsrr/drugoverdose-data.htm [Accessed 19 Apr 2021].

2 Degenhardt L, Grebely J, Stone J, et al. Global patterns of opioid use and dependence: harms to populations, interventions, and future action. Lancet 2019;394:1560-79.

3 Mathers BM, Degenhardt L, Phillips B, et al. Global epidemiology of injecting drug use and HIV among people who inject drugs: a systematic review. Lancet 2008;372:1733-45.

4 Suchman NE, DeCoste C, Borelli JL, et al. Does improvement in maternal attachment representations predict greater maternal sensitivity, child attachment security and lower rates of relapse to substance use? a second test of Mothering from the inside out treatment mechanisms. J Subst Abuse Treat 2018;85:21-30.

5 Suchman NE, DeCoste CL. Substance abuse and addiction: implications for early relationships and interventions. Zero Three 2018;38:17

6 Rudd RA, Seth P, David F, et al. Increases in drug and opioidinvolved overdose deaths-United States, 2010-2015. MMWR Morb Mortal Wkly Rep 2016;65:1445-52.

7 Daubresse M, Chang $\mathrm{H}-\mathrm{Y}, \mathrm{Yu}$ Y, et al. Ambulatory diagnosis and treatment of nonmalignant pain in the United States, 2000-2010. Med Care 2013;51:870-8.

8 Dowell D, Haegerich TM, Chou R. CDC guideline for prescribing opioids for chronic pain - United States, 2016. JAMA 2016;315:1624-45.

9 D'Souza RS, Lang M, Eldrige JS. Prescription drug monitoring program. in: StatPearls. Treasure Island, FL: StatPearls Publishing, 2021. http://www.ncbi.nlm.nih.gov/books/NBK532299/

10 Cabana MD, Rand CS, Powe NR, et al. Why don't physicians follow clinical practice guidelines? A framework for improvement. JAMA 1999;282:1458-65

11 Asamoah-Boaheng M, Badejo OA, Bell LV, et al. Interventions to influence opioid prescribing practices for chronic noncancer pain: a systematic review and meta-analysis. Am J Prev Med 2021;60:e15-26.

12 Quanbeck A, Almirall D, Jacobson N, et al. The balanced opioid initiative: protocol for a clustered, sequential, multiple-assignment randomized trial to construct an adaptive implementation strategy to improve guideline-concordant opioid prescribing in primary care. Implement Sci 2020;15:26.

13 Powell BJ, Waltz TJ, Chinman MJ, et al. A refined compilation of implementation strategies: results from the expert recommendations for implementing change (ERIC) project. Implement Sci 2015;10:1-14.

14 Ferlie EB, Shortell SM. Improving the quality of health care in the United Kingdom and the United States: a framework for change. Milbank Q 2001;79:281-315.

1515 Jacobson N, Johnson R, Deyo B, et al. Systems consultation for opioid prescribing in primary care: a qualitative study of adapation. BMJ: Quality and Safety 2019.

16 Pawson R, Greenhalgh T, Harvey G. Realist synthesis: an introduction. Manchester: ESRC research methods programme. University of Manchester, 2004: 1-55.

17 Shaw J, Gray CS, Baker GR, et al. Mechanisms, contexts and points of contention: operationalizing realist-informed research for complex health interventions. BMC Med Res Methodol 2018;18:1-12.

18 Rycroft-Malone J, McCormack B, Hutchinson AM, et al. Realist synthesis: illustrating the method for implementation research. Implement Sci 2012;7:33.

19 Harris JL, Booth A, Cargo M, et al. Cochrane qualitative and implementation methods group guidance series-paper 2: methods for question formulation, searching, and protocol development for qualitative evidence synthesis. J Clin Epidemiol 2018;97:39-48.

20 Allen MJM, Asbridge MM, Macdougall PC, et al. Self-reported practices in opioid management of chronic noncancer pain: a survey of Canadian family physicians. Pain Res Manag 2013;18:177-84. 
21 Anderson D, Zlateva I, Khatri K, et al. Using health information technology to improve adherence to opioid prescribing guidelines in primary care. Clin J Pain 2015;31:573.

22 Anderson DR, Zlateva I, Coman EN, et al. Improving pain care through implementation of the stepped care model at a multisite community health center. J Pain Res 2016;9:1021.

23 Ball S, Wilson B, Ober S, et al. SCAN-ECHO for pain management: implementing a regional telementoring training for primary care providers. Pain Med 2018;19:262-8.

24 Bauer SR, Hitchner L, Harrison H, et al. Predictors of higher-risk chronic opioid prescriptions in an academic primary care setting. Subst Abus 2016;37:110-7.

25 Becker WC, Mattocks KM, Frank JW, et al. Mixed methods formative evaluation of a collaborative care program to decrease risky opioid prescribing and increase non-pharmacologic approaches to pain management. Addict Behav 2018;86:138-45.

26 Blake H, Leighton P, van der Walt G, et al. Prescribing opioid analgesics for chronic non-malignant pain in general practice-a survey of attitudes and practice. Br J Pain 2015;9:225-32.

27 Buchman DZ, Ho A, Illes J. You present like a drug addict: patient and clinician perspectives on trust and trustworthiness in chronic pain management. Pain Med 2016;17:1394-406.

28 Buchman DZ, Ho A. What's trust got to do with it? Revisiting opioid contracts. J Med Ethics 2014;40:673-7.

29 Burgess DJ, Phelan S, Workman M, et al. The effect of cognitive load and patient race on physicians' decisions to prescribe opioids for chronic low back pain: a randomized trial. Pain Med 2014:15:965-74.

30 Canada RE, DiRocco D, Day S. A better approach to opioid prescribing in primary care. J Fam Pract 2014;63:E1-8.

31 Cardarelli R, Workman CS, Weatherford S, et al. Dissemination approaches to participating primary care providers in a quality improvement program addressing opioid use in central appalachia. South Med J 2017;110:421-4.

32 Chang JS, Kushel M, Miaskowski C, et al. Provider experiences with the identification, management, and treatment of co-occurring chronic noncancer pain and substance use in the safety net. Subst Use Misuse 2017;52:251-5.

33 Chen JH, Hom J, Richman I, et al. Effect of opioid prescribing guidelines in primary care. Medicine 2016;95:e4760.

34 Click IA, Basden JA, Bohannon JM, et al. Opioid prescribing in rural family practices: a qualitative study. Subst Use Misuse 2018;53:533-40.

35 Cox N, Tak CR, Cochella SE, et al. Impact of pharmacist previsit input to providers on chronic opioid prescribing safety. J Am Board Fam Med 2018;31:105-12.

36 Dorflinger LM, Ruser C, Sellinger J, et al. Integrating interdisciplinary pain management into primary care: development and implementation of a novel clinical program. Pain Med 2014;:15:2046-54.

37 Ebbert JO, Philpot LM, Clements CM, et al. Attitudes, beliefs, practices, and concerns among clinicians prescribing opioids in a large academic institution. Pain Med 2018;19:1790-8.

38 Fisher K. Improving use of opioid safety in primary care, 2019. Available: https://repository.arizona.edu/handle/10150/631286 [Accessed 8 Apr 2021].

39 Fleming ML, Driver L, Sansgiry SS, et al. Physicians' intention to prescribe hydrocodone combination products after rescheduling: a theory of reasoned action approach. Res Social Adm Pharm 2017;13:503-12.

40 Gaiennie CC, Dols JD. Implementing evidence-based opioid prescription practices in a primary care setting. $J$ Nurse Practit 2018;14:e143-7.

41 Giannitrapani KF, Glassman PA, Vang D, et al. Expanding the role of clinical pharmacists on interdisciplinary primary care teams for chronic pain and opioid management. BMC Fam Pract 2018;19:1-9.

42 Harle CA, Bauer SE, Hoang HQ, et al. Decision support for chronic pain care: how do primary care physicians decide when to prescribe opioids? A qualitative study. BMC Fam Pract 2015;16:1-8.

43 Hawkins EJ, Malte CA, Hagedorn HJ, et al. Survey of primary care and mental health prescribers' perspectives on reducing opioid and benzodiazepine co-prescribing among Veterans. Pain Med 2017;18:454-67.

44 Holliday S, Magin P, Dunbabin J, et al. An evaluation of the prescription of opioids for chronic nonmalignant pain by Australian general practitioners. Pain Med 2013;14:62-74.

45 Holliday SM, Hayes C, Dunlop AJ, et al. Does brief chronic pain management education change opioid prescribing rates? A pragmatic trial in Australian early-career general practitioners. Pain 2017;158:278-88.
46 Hughes HK, Korthuis PT, Saha S, et al. A mixed methods study of patient-provider communication about opioid analgesics. Patient Educ Couns 2015;98:453-61.

47 Hulen E, Saha S, Morasco BJ, et al. Sources of distress in primary care opioid management and the role of a controlled substance review group: a qualitative study. Pain Med 2018;19:1570-7.

48 Hwang CS, Turner LW, Kruszewski SP, et al. Primary care physicians knowledge and attitudes regarding prescription opioid abuse and diversion. Clin J Pain 2016;32:279-84.

49 Hwang CS, Turner LW, Kruszewski SP, et al. Prescription drug abuse: a national survey of primary care physicians. JAMA Intern Med 2015:175:302-4.

50 Irvine JM, Hallvik SE, Hildebran C, et al. Who uses a prescription drug monitoring program and how? Insights from a statewide survey of Oregon clinicians. J Pain 2014;15:747-55.

51 Jamison RN, Scanlan E, Matthews ML, et al. Attitudes of primary care practitioners in managing chronic pain patients prescribed opioids for pain: a prospective longitudinal controlled trial. Pain Med 2016;17:99-113.

52 Jamison RN, Sheehan KA, Scanlan E, et al. Beliefs and attitudes about opioid prescribing and chronic pain management: survey of primary care providers. J Opioid Manag 2014;10:375-82.

53 Jeffrey Kao M-C, Minh LC, Huang GY. Trends in ambulatory physician opioid prescription in the United States, 1997-2009. PM\&R 2014;6:575-82.

54 Kavukcu E, Akdeniz M, Avci HH, et al. Chronic noncancer pain management in primary care: family medicine physicians' risk assessment of opioid misuse. Postgrad Med 2015;127:22-6.

55 Kennedy-Hendricks A, Busch SH, McGinty EE, et al. Primary care physicians' perspectives on the prescription opioid epidemic. Drug Alcohol Depend 2016;165:61-70.

56 Khalid L, Liebschutz JM, Xuan Z, et al. Adherence to prescription opioid monitoring guidelines among residents and attending physicians in the primary care setting. Pain Med 2015;16:480-7.

57 Knight KR, Kushel M, Chang JS, et al. Opioid pharmacovigilance: a clinical-social history of the changes in opioid prescribing for patients with co-occurring chronic non-cancer pain and substance use. Soc Sci Med 2017;186:87-95.

58 Krebs EE, Bergman AA, Coffing JM, et al. Barriers to guidelineconcordant opioid management in primary care--a qualitative study. $J$ Pain 2014:15:1148-55.

59 Lange A, Lasser KE, Xuan Z, et al. Variability in opioid prescription monitoring and evidence of aberrant medication taking behaviors in urban safety-net clinics. Pain 2015;156:335-40.

60 Leichtling G, Hildebran C, Novak K, et al. Physician responses to enhanced prescription drug monitoring program profiles. Pain Med 2020;21:e9-21.

61 Leichtling GJ, Irvine JM, Hildebran C, et al. Clinicians' use of prescription drug monitoring programs in clinical practice and decision-making. Pain Med 2017;18:1063-9.

62 Liebschutz JM, Xuan Z, Shanahan CW, et al. Improving adherence to long-term opioid therapy guidelines to reduce opioid misuse in primary care: a cluster-randomized clinical trial. JAMA Intern Med 2017:177:1265-72

63 Lin DH, Lucas E, Murimi IB, et al. Physician attitudes and experiences with Maryland's prescription drug monitoring program (PDMP). Addiction 2017:112:311-9.

64 Macerollo AA, Mack DO, Oza R, et al. Academic family medicine physicians' confidence and comfort with opioid analgesic prescribing for patients with chronic nonmalignant pain. J Opioid Manag 2014;10:255-61.

65 Mathieson S, Valenti L, Maher CG, et al. Worsening trends in analgesics recommended for spinal pain in primary care. Eur Spine $J$ 2018;27:1136-45.

66 Matthias MS, Krebs EE, Bergman AA, et al. Communicating about opioids for chronic pain: a qualitative study of patient attributions and the influence of the patient-physician relationship. Eur J Pain 2014:18:835-43.

67 McCracken LM, Boichat C, Eccleston C. Training for general practitioners in opioid prescribing for chronic pain based on practice guidelines: a randomized pilot and feasibility trial. $J$ Pain 2012;13:32-40.

68 McCrorie C, Closs SJ, House A, et al. Understanding long-term opioid prescribing for non-cancer pain in primary care: a qualitative study. BMC Fam Pract 2015;16:1-9.

69 McGee S, Silverman RD. Treatment agreements, informed consent, and the role of state medical boards in opioid prescribing. Pain Med 2015;16:25-9.

70 McKinlay JB, Trachtenberg F, Marceau LD, et al. Effects of patient medication requests on physician prescribing behavior: results of a factorial experiment. Med Care 2014;52:294. 
71 Militello LG, Anders S, Downs SM. Understanding how primary care clinicians make sense of chronic pain. Cognition, Technology \& Work 2018;20:575-84.

72 Nguyen TD, Bradford WD, Simon KI. Pharmaceutical payments to physicians may increase prescribing for opioids. Addiction 2019;114:1051-9.

73 Onishi E, Kobayashi T, Dexter E, et al. Comparison of opioid prescribing patterns in the United States and Japan: primary care physicians' attitudes and perceptions. J Am Board Fam Med 2017;30:248-54.

74 Patchett D, Grover M, Kresin M, et al. The benefits of a standardized approach to opioid prescribing. J Fam Pract 2019;68:E1-7.

75 Penti B, Liebschutz JM, Kopcza B, et al. Novel peer review method for improving controlled substance prescribing in primary care. $J$ Opioid Manag 2016;12:269-79.

76 Price-Haywood EG, Robinson W, Harden-Barrios J, et al. Intelligent clinical decision support to improve safe opioid management of chronic noncancer pain in primary care. Ochsner J 2018;18:30-5.

77 Provenzano DA, Kamal KM, Giannetti V. Evaluation of primary care physician chronic pain management practice patterns. Pain Physician 2018;21:E593-602.

78 Ringwalt C, Gugelmann H, Garrettson M, et al. Differential prescribing of opioid analgesics according to physician specialty for Medicaid patients with chronic noncancer pain diagnoses. Pain Res Manag 2014;19:179-85.

79 Rutkow L, Turner L, Lucas E, et al. Most primary care physicians are aware of prescription drug monitoring programs, but many find the data difficult to access. Health Aff 2015;34:484-92.

80 Seamark D, Seamark C, Greaves C, et al. GPs prescribing of strong opioid drugs for patients with chronic non-cancer pain: a qualitative study. Br J General Pract 2013;63:e821-8.

81 Shields CG, Fuzzell LN, Christ SL, et al. Patient and provider characteristics associated with communication about opioids: an observational study. Patient Educ Couns 2019;102:888-94.

82 Starrels JL, Wu B, Peyser D, et al. It made my life a little easier: primary care providers' beliefs and attitudes about using opioid treatment agreements. J Opioid Manag 2014;10:95-102.
83 Sullivan MD, Leigh J, Gaster B. Brief report: training internists in shared decision making about chronic opioid treatment for noncancer pain. J Gen Intern Med 2006;21:360-2.

84 Turk DC, Dansie EJ, Wilson HD, et al. Physicians' beliefs and likelihood of prescribing opioid tamper-resistant formulations for chronic noncancer pain patients. Pain Med 2014;15:625-36.

85 Weimer MB, Hartung DM, Ahmed S, et al. A chronic opioid therapy dose reduction policy in primary care. Subst Abus 2016;37:141-7.

86 Westanmo A, Marshall P, Jones E, et al. Opioid dose reduction in a VA health care system-implementation of a primary care population-level initiative. Pain Med 2015;16:1019-26.

87 White R, Hayes C, Boyes AW, et al. General practitioners and management of chronic noncancer pain: a cross-sectional survey of influences on opioid deprescribing. J Pain Res 2019;12:467-75.

88 Witt TJ, Deyo-Svendsen ME, Mason ER, et al. A model for improving adherence to prescribing guidelines for chronic opioid therapy in rural primary care. Mayo Clin Proc Innov Qual Outcomes 2018;2:317-23

89 Wong R, Carroll W, Muttreja A, et al. Improving opioid management and resource utilization in an internal medicine residency clinic: a before-after study over two plan-do-study-act cycles. Pain Med 2019;20:1919-24.

90 Jagosh J. Realist synthesis for public health: building an ontologically deep understanding of how programs work, for whom, and in which contexts. Annu Rev Public Health 2019;40:361-72.

91 Lau R, Stevenson F, Ong BN. Achieving change in primary carecauses of the evidence to practice gap: systematic reviews of reviews. Implement Sci 2016;11:1-39.

92 Kertesz SG, McCullough MB, Darnall BD, et al. Promoting Patient-Centeredness in opioid deprescribing: a blueprint for Deimplementation science. J Gen Intern Med 2020;35:972-7.

93 Pergolizzi JV, Varrassi G, Paladini A, et al. Stopping or decreasing opioid therapy in patients on chronic opioid therapy. Pain Ther 2019;8:163-76. 